\title{
REINFORCEMENT EFFECT OF POLYETHYLENE FIBER TO COMPOSITE CORES OF ENDODONTICALLY TREATED TEETH
}

\author{
Ziad H. Rabie*
}

\begin{abstract}
Statement of problem: Severely damaged teeth frequently require placement of a core before preparation to receive an indirect restoration. However, the choice of the core material may also influence the outcome although reliable research data are scare.

Purpose: The purpose of this study was to evaluate the effect of short fiber-reinforced composite resin of endodontically treated teeth restored with and without root canal posts.

Methods: Sixty human extracted maxillary incisors were sectioned at the cemento-enamel junction. The root canals were prepared and obturated with gutta percha. Three groups of direct complete crowns were fabricated ( $n=20$ per group); Group A: made from particulate filler composite resin (Corestore 2, Kerr, control), Group B: particulate filler composite resin with fiber post (Aestheti-Post; Bisco), Group C: made from particulate filler composite resin with fiber post and short polyethylene fibers substructure (Ribbond Inc.). After finishing and polishing, the specimens were stored in $100 \%$ humidity at $37^{\circ} \mathrm{C}$ for 24 hours before they were statically loaded with a cross-head speed of $0.5 \mathrm{~mm} / \mathrm{min}$ until fracture. Data were analyzed with 1-way ANOVA followed by Ryan-Einot-Gabriel-Welsch multiple-range test $(\alpha=.05)$.
\end{abstract}

Results: ANOVA revealed that restorations made from particulate filler composite resin with fiber post and short polyethylene fibers substructure had higher fracture resistance capacity (309 $\mathrm{N})(\mathrm{p}<0.05)$ than restorations made from particulate filler composite resin with fiber post $(258 \mathrm{~N})$. Control group had significant lower fracture resistance $(178 \mathrm{~N})(\mathrm{P}<0.05)$.

Conclusion: Polyethylene fiber may be an effective and practical method for reinforcement of the composite core material of endodontically treated teeth.

\section{INTRODUCTION}

Compared to teeth with healthy pulps, root filled teeth are considered more susceptible to fracture as they posses reduced dentinal elasticity, ${ }^{1,2}$ Lower water content, ${ }^{3}$ deeper cavities, ${ }^{4}$ and substantial loss of dentin. ${ }^{5}$ The structural rehabilitation of a root filled tooth is critically important to ensure a successful restorative outcome following endodontic treatment. ${ }^{6}$

* Lecturer of Fixed Prosthodontics Faculty of Dentistry October 6 University 
A post and core is often indicated for the retention and reinforcement of the final restoration. A number of guidelines have been suggested for restoring endodontically treated teeth, and they are supported by research finding, literature reviews, and retrospective clinical studies. ${ }^{7}$ The guidelines aid the practitioner in choosing which core system was be used to retain the final restoration in endodontically treated teeth. ${ }^{8}$

Previous studies indicated that amalgam restorations, composite resin, and glass ionomer can be used for final restorations. ${ }^{9,10}$ Variations of the latter material include resin-modified glass ionomers, compomers, ceramometals and metalmodified glass ionomers. The properties of the ideal core material includes; incompatibility, cariostatic activity, bonds to tooth/luting agent, adequate compressive/flextural strengths, low thermal diffusivity, coefficient of thermal expansion comparable to dentin, comparable with temporary cements, contrasting color to tooth/esthetic, dimensional stability, ease of mixing/placement, short setting time, reasonable cost, good shelf life, radiopaque, and non-allergic. However, in the selection of a suitable material, the clinician must consider the eventual shape of the preparation and assess the effect of reduction upon the core material. With complex treatment plans, the core may serve as a transitional restoration for an extended period of time and so the material must be capable of maintaining occlusal stability and patient comfort. ${ }^{11}$

Dental amalgam is often the material of choice for cores on posterior teeth, but it has a number of deficiencies. Possibly the most important concerns are the safety and environmental issues associated with mercury. ${ }^{12}$ At present, the safety issue remains unproven. ${ }^{13}$ But amalgam's weak tensile and flextural strengths make it brittle in thin sections and its compressive strength develops progressively following trituration. Spherical, copper-enriched alloys achieve this strength faster and it is possible to prepare core after only $10-15$ minutes.${ }^{14}$ However, preparation has to be delayed for at least 24 hours. Despite these limitations, amalgam remains an indispensable material for restoring broken down posterior teeth.

Glass ionomer cement, resin-modified glass ionomer and metal-modified glass ionomer have all been advocated for direct cores. ${ }^{11}$ Conventional glass ionomer have recently been improved by high powder-to-liquid ratios, lower water contents, and much smaller glass particles. This leads to higher viscosity. Cements have metals sintered to the glass particles, whereas metal-modified glass ionomer have metal powders added to the cement mix. Hydroxyethyl methacrylate (HEMA) is added to resin modified glass ionomer by two mechanisms, an acid base reaction and resin polymerization which is initiated chemically or by light or both. Although glass ionomer posses some advantages as their chemical bonding to dentin and enamel, fluoride release, similar thermal expansion to tooth and one visit core placement and preparation technique they have some draw backs that includes inferior compressive and tensile strengths and the role of water in the setting reaction..$^{15}$ Resin modified glass ionomer have much improved physical properties compared to their conventional counterparts. ${ }^{14}$ However metal -modified glass ionomer do not appear to offer improved clinical performance when data from deciduous tooth studies are considered. ${ }^{16}$ Water contamination during the setting reaction alters color, increases surface roughness, irreversibly affects strength and produces volume changes. Therefore, it is recommended that preparation of a glass ionomer core be delayed for at least 24 hours after placement. Expansion from water absorption may lead to all-ceramic crown fracture ${ }^{17}$ or tighter fitting metal castings. ${ }^{18}$

A wide variety of composite resins can be used for core restorations. These include hybrid, microhybrid, high viscosity and bespoke 
composites. ${ }^{19,20}$ Composite resins are popular for cores because of appearance, the possibility of single visit core placement and preparation, and reliable bonding strengths..$^{21,22}$ Composites have compressive strengths comparable to amalgam, while tensile and flexural strengths are superior. ${ }^{19}$ Polymerization contraction stresses on the tooth can increase the risk of marginal leakage, post-operative sensitivity, secondary caries, or in some cases cuspal flexure or fracture..$^{20}$ Bulk curing composite increases these stresses but cores are often placed in cavities with few opposing walls. In addition, bulk placement prevents light penetration to the tooth/ composite interface..$^{23,24}$

The development of fiber-reinforced composite technology has increased used of composite resin materials in extensive preparations. Reinforcing the resin with glass fibers, ${ }^{25}$ with fiber-reinforced composite resin substructure, ${ }^{26}$ whiskers, ${ }^{27}$ particulate ceramic fillers, ${ }^{28}$ and optimization of filler content are among the methods that have been studied. ${ }^{29}$ Other aspects relating to indirect laboratory-made composite resins have been investigated using post-polymerizing to enhance composite resin strength and toughness. ${ }^{30} \mathrm{~A}$ finite element stress analysis study also reported that fiber-reinforced composite post and core systems provide more adequate restoration by protecting the remaining tooth tissue with its elastic modulus close to dentin when compared with the conventional rigid post-core systems. ${ }^{31}$

For over 30 years, glass fibers have been investigated to reinforce dental polymers. ${ }^{32}$ The effectiveness of fiber reinforcement is dependent on many variables, including the resins used, the quantity of fibers in the resin matrix, ${ }^{33}$ length of fibers ${ }^{34}$ form of fibers, ${ }^{35}$ orientation of fibers, ${ }^{36}$ adhesion of fibers to the polymer matrix, ${ }^{37}$ and impregnation of fibers with the resin. ${ }^{38}$ Short random fibers provide an isotropic reinforcement effect in multidirections instead of 1 or 2 directions, as described by Krenchel.$^{39}$ It has been hypothesized that using these new materials and techniques enable the practitioner to approach old problems from a different perspective and thereby achieve unique and innovative solutions. Although there are many studies with fiber-reinforced composite in the literature, the effect of fiber insertion as stress breaker within extensive composite cores has not been studied. The purpose of this study was to evaluate the effect of using leno woven high modulus polyethylene fiber to reinforcement composite cores of endodontically treated teeth. The null hypothesis was that creating an elastic layer under a composite cores using leno woven ultra high molecular weight polyethylene fiber ribbon would increase the fracture strength of endodontically treated teeth with composite cores.

\section{MATERIALS AND METHODS}

Sixty freshly extracted human maxillary central incisors with straight roots and completely formed apices were selected on the basis of similar root sizes, absence of caries in the root, a crown up to $2 \mathrm{~mm}$ above the cemento-enamel junction (CEJ), and absence of visible fracture lines in the root. The teeth were stored in an aqueous $1 \%$ chloramine-T solution to inhibit bacterial growth and kill any pathogenic organisms. Teeth were selected for similarity in size, shape, and root anatomy. Teeth were then transiluminated with fiber-optic light to ensure absence of surface cracks, and fractures. Teeth were radiographically examined to confirm similarity in internal root diametric thickness and coronal configuration. Those without serious defects were cleaned of any remaining soft tissue with a curette, storage and returned to fresh aqueous $1 \%$ chloramines- T solution until testing begins. Storage was at ambient room temperature. Teeth were randomly assigned (three blindfolded colleagues selecting 20 specimens each) to three experimental groups. 
Group I served as a control group for comparison; the crowns of the rest specimens were prepared as follow: Crowns were reduced perpendicular to the root axis, leaving 1.00 to $2.00 \mathrm{~mm}$ above the cementoenamel junction. The root canal of each tooth were instrumented with a conventional step back technique to an International Standardization Organization (ISO) file size of 35 at the optical constriction. The canals were irrigated with $5 \%$ sodium hypochlorite throughout preparation and dried with paper points. All teeth were held by hand during instrumentation, and the plane of greatest curvature was aligned parallel to the plane of oscillation of the file.

Each canal was widened manually by a single operator. A syringe fitted with a 27-gauge needle was used for this purpose. The needle was placed passively in the coronal access cavity, and irrigation was carried into the root canal between each file size and as a final flush. The maximum depth of penetration of the needle tip/file was 1-2 mm from the apical foramen with the foramen oriented downward and the access opening upward to allow more irrigant solution to penetrate apically. Each canal was obturated by lateral condensation of gutta-percha points against an ISO 35 primary guttapercha cone. Ketac-Endo root canal cement, which contains no eugenol, was used as the sealer. Guttapercha was then removed from each canal until 4 $\mathrm{mm}$ of material remained at the apex and $10.5 \mathrm{~mm}$ dowel space length achieved.

After canal obturation, a dowel space was prepared in each sample to a standardized length. An instrument was used to soften and remove guttapercha to the desired depth. The length of the dowel space was verified with a periodontal probe fitted with an endodontic reference stop and a radiograph. Then the corresponding drill to each dowel was used to prepare the dowel space to the desired depth. All dowels (Para post; Coltene/Whaledent, Cuyahoga Falls, $\mathrm{OH}$ ) were cemented with resin luting cement (Panavia 21; Kurrary Co., LTD, Tustin, CA) following the manufacturer instructions. Two experimental groups were prepared according to core build-up. Group II, composite resin core (Prodigy, Kerr,); Group III, composite resin core reinforced with leno woven ultra high modulus polyethylene fiber (Ribbond; Seattle).

Composite cores extending $6 \mathrm{~mm}$ incisal to the sectioned tooth surfaces was fabricated with polyester central incisor-shaped matrices (Kerr) seated over the dowels' crown portion. First, coronal tooth surfaces was etched for 15 seconds with $32 \%$ phosphoric acid, rinsed, and air dried. Two layers of OptiBond Solo Plus bonding agent (Kerr) was applied to the cervical dentin and the coronal portion of the dowel, and polymerized for 20 seconds. For each specimen, equal measures of composite resin were loaded into a syringe (Centrix CR EZ Syringe; Centrix, Shelton, Conn) and carefully applied to the tooth surface to avoid air entrapment. In order to minimize variations in specimens, a transparent template matrix (Memosil 2, Heraeus Kulzer, Germany) of an ideally contoured crown was used to aid crown fabrication for all groups. The core was then polymerized with a wide-tipped prismatic lightpolymerizing unit (Optilux VCL 401, at $420 \mathrm{~mW}$ / $\mathrm{cm} 2$; Kerr Corp, Orange, Calif ) for 40 seconds on each of the 5 surfaces. Fiber reinforced composite substructure layers were placed over the flattened incisal surface. The orientation of the two fiber layers was opposite to each other in order to have fiber reinforcement in all directions using titanium nitride coated instruments (Brilliant Esthetic Line Composite Instrument; Coltène/Whaledent, Inc). The preformed template matrix was then removed with a surgical blade. After finishing and polishing, the specimens were stored in $100 \%$ humidity at $37^{\circ} \mathrm{C}$ for 24 hours.

The root of each restored tooth was thinly covered with self-curing rubber to simulate a periodontal ligament and embedded in acrylic an epoxy resin blocks so that $2.00 \mathrm{~mm}$ of the natural 
root structure was exposed. The specimens were coded and randomly chosen for transverse loading in an Instron testing device. The machine applied a compressive load against the predesigned indentation on the lingual aspect of the core buildup, $2 \mathrm{~mm}$ below the incisor edge. The lingually directed load simulated a Class I occlusal contact angle. The load was applied at a 130-degree angle to the long axis by use of a steel rod with a rounded end. Transverse loading was maintained under a constant crosshead speed of $0.5 \mathrm{~mm} / \mathrm{min}$ until failure occurred, as measured by sudden release of load on the specimen. The fracture mode was then recorded, and fracture mode representative specimens from each group were selected and photographed. The data were analyzed with 1-way analysis ANOVA followed by Ryan-Einot-Gabriel-Welsch multiplerange test $(\alpha=.05) .^{30}$

\section{RESULTS}

There were no statistically significant differences between the two experimental groups regarding the use of polyethylene fibers. However, the differences were significant with the control group $(\mathrm{P}>0.05)$ as shown in Table 1.

TABLE (1) 1-way repeated measure ANOVA for fracture resistance.

\begin{tabular}{lcccc}
\hline Source & $D f$ & MS & F & $P$ \\
\hline Fracture resistance & 2 & 22.2 & 6.59 & $<0.05$ \\
Error & 57 & 3.4 & & \\
\hline
\end{tabular}

$d f=$ degree offreedom; $M S=$ mean square $P=$ probabilities

Table 2 summarizes the mean fracture loads and standard deviations for the 3 test groups. ANOVA revealed no statistically significant difference in load-bearing capacity between restorations reinforced with fiber reinforced composite resin substructure 309 (126)c and those without 258 (109)b. Control group had significant lower load-bearing capacity 178 (134)a.
TABLE (2) Fracture resistance among experimental groups (mean (SD)) $(\mathrm{n}=20)$.

\begin{tabular}{lc}
\hline Group & $\begin{array}{c}\text { Mean } \\
\text { (Standard deviation) }\end{array}$ \\
\hline Control & $178(134)^{\mathrm{a}}$ \\
Conventional composite resin & $258(109)^{\mathrm{b}}$ \\
Fiber reinforced composite resin & $309(126)^{\mathrm{c}}$ \\
\hline
\end{tabular}

Values with the same lower case letters are not significantly different at $P<.05$.

\section{DISCUSSION}

The data support rejection of the null hypothesis of the study, that there would be no difference in the fracture strengths of endodontically treated teeth regardless to the use of polyethylene fibers for strengthening the composite resin core. The increased demand for clinically convenient treatment to restore endodontically treated teeth has provided clinicians with a number of simplified dowel and core based restorative options.$^{40}$ However, abundant choices can present an understandably difficult situation for clinicians trying to select the best materials and techniques for an optimal result.

Results obtained in this investigation supported the hypotheses of using fiber reinforced composite substructure to reinforce the composite resin restoration in order to sustain loads of direct complete incisor crowns. This study simulated the worst case scenario of endodontically treated maxillary incisors with severely damaged crowns. Conventional treatment would have involved a metal post-and-core and a complete crown. Conversely, clinical studies on failure of metal post and core restorations often reported the incidence of root fracture. ${ }^{1,2}$ Composite resin or amalgam would have been alternative core materials. Good long-term clinical performance of endodontically treated teeth restored with a combination of fiber post and composite resin core in combination to dentin bonding were reported..$^{20,22}$ However, another 
study has reported lower long-term survival rates with the primary cause of failure being fracture of the composite resin restoration, especially in high stress-bearing areas. ${ }^{24}$ It was hypothesized that using polyethylene fiber fillers could reinforce the composite resin restoration to maintain loads of direct complete crowns. The results of the current study revealed substantial improvement in the load bearing capacity of dental composite resin reinforced with polyethylene fiber fillers in comparison with conventionally used restorative composite resins. In order for the fiber to act as an effective reinforcement for polymers, stress transfer from the polymer matrix to the fibers is essential, ${ }^{25}$ and is achieved by having fiber length equal to or greater than the critical fiber length. ${ }^{41}$ Based on this knowledge, the present study used fiber fillers $3 \mathrm{~mm}$ in length. In theory, the reinforcing effect of the fiber fillers is based not only on stress transfer from the polymer matrix to the fibers, but also on the behavior of individual fibers as stress breakers.

In the current study, specimen teeth with similar root morphology and mesiodistal and buccolingual dimensions were selected. The small variations in root measurements minimized variations in the thickness of the intermediate layer. There were some limitations in the present study. Though the test method used in the current study attempted to simulate the clinical situation, the unidirectional static loading force applied did not replicate the complex dynamic forces present in the oral environment during mastication and with parafuctional habits. However, a unidirectional static loading force was selected in the current study and in many other studies of root fractures to minimize the experimental variables ${ }^{42-44}$ Clinically, root fractures in maxillary anterior teeth restored with dowel-cores and artificial crowns are more likely to occur from cyclic fatigue and single severe impacts. ${ }^{45}$ Further laboratory testing should more closely simulate these two factors. The angulation between the long axis of the anterior teeth also can significantly affect the in vitro loading forces required for the fracture of dowel-core restored roots ${ }^{46}$ Another limitation of this study was that the ferrule effect was not observed to enable the load force to be transferred from the restoration to the root structure. Also, aging processes, such as alternate thermal stress, mechanical stress, wear, and water storage should also be taken into consideration.

\section{CONCLUSION}

Within the limitations of this study, the following conclusions were drawn:

1. Fiber reinforced composite resin demonstrated improved fracture resistance capacity compared with conventional composite resin particulate filler restorative composite resin.

2. Use of a continuous bidirectional polyethylene fiber-reinforced composite substructure at the interface of composite resin crown and dentin may aid in eliminating crack propagation and root fractures.

\section{REFERENCES}

1. Creugers NHJ, Mentink AGB, Ka“yser AF. An analysis of durability data on post and core restorations. J Dent $1993 ; 21: 281-4$.

2. Testori T, Badino M, Castagnola M. Vertical root fractures in endodontically treated teeth: a clinical survey of 36 cases. J Endodont 1993;19:87-90.

3. Helfer AR, Melnick S, Schilder H. Determination of the moisture content of vital and pupless teeth. Oral Surg Oral Medicine Oral Pathol 1972;34:661-70.

4. Madison S, Wilcox LR. An evaluation of coronal micro leakage in endodontically treated teeth. Part III. In vivo study. J Endod 1988;14:455-8.

5. Assif D, Nissan J, Gafni Y, Gordon M. Assessment of the resistance to fracture of endodontically treated molars restored with amalgam. J Prosthet Dent 2003;89:462-5.

6. Wagnild GM, Mueller KI. Restoration of the endodontically treated tooth. In: Cohen S. Bums RC, ed Pathway of the pulp. 8th ed. St Louis: Mosby Inc, 2014:. P. 765. 
7. Gluskin AH, Radke RA, Forost SL, Watanabe LG. The mandibular incisor: Rethinking guidelines for post and core design. J Endod 1995;21:33-7.

8. Rosenstiel SF, Land MF, Fujimoto J. Contemporary fixed prosthodontics. 5th ed. St Louis: Mosby Inc, 2015. P.336.

9. Smales RJ, Hawthorne WS. Long-term survival of extensive amalgams and posterior crowns. J Endod 1997; 25:225-7.

10. Hernandez R, Bader S, Boston D, Trope M. resistance to fracture of endodontically treated premolars restored with new generation dentin bonding systems. Int Endodont $\mathrm{J}$ 1994;27:281-4.

11. Sidhu SK, Watson TF. Resin-modified glass ionomer materials. A status report for the American Journal of Dentistry. Am J Dent 1995;8:59-67.

12. Dodes JE. The amalgam controversy. An evidence based analysis. J Am Dent Assoc 2001;132:348-356.

13. Wahl MJ. Amalgam-Resurrection and redemption. Part 2: The medical mythology of anti-amalgam. Quintessence Int 2001;32:696-710.

14. Christensen GJ. When to use fillers, build-ups or post and cores. J Am Dent Assoc 1996;127: 1397-8.

15. Naasan MA, Watson TF. Conventional glass ionomers as posterior restorations. A status report for the American Journal of Dentistry. Am J Dent 1998;11 :36-45.

16. Kramer N, Frankenberger R. Clinical performance of a condensable metal-reinforced glass ionomer cement in primary molars. Br Dent J 2001;189:317-21.

17. Azer SS, Drummond JL, Campbel SD, EI-Moneim Zaki A. Influence of core buildup material on the fatigue strength of an all-ceramic crown. J Prosthet Dent 2001;86:624-31.

18. Olivia RA, Lowe JA. Dimensional stability of silver amalgam and composite used as core materials. J Prosthet Dent 1987;57:554-9.

19. Come EC, Burke FJT. Contemporary resin-based composite materials for direct placement restorations: packables, flowable and others. Dent Update 2000;27:326-36.

20. Roeters JJ. Extended indications for directly bonded composite restorations: a clinician's view. J Adhes Dent 2001;3:81-7.

21. Suzuki MM. Recent commercial composite formulations. Oper Dent 2001;SuppI6:145-51.
22. Grandini S, Goracci C, Tay FR, Grandini R, Ferrari M. Clinical evaluation of the use of fiber posts and direct resin restorations for endodontically treated teeth. Int $\mathrm{J}$ Prosthodont 2005;18:399-404.

23. Feilzer AK, DeGee AJ, Davidson CL. Setting stress in composite resin in relation to the configuration of the restoration. J Dent Res 1987;66:1636-9.

24. Fraga RC, Chaves BT, Mello GS, Siqueira Jr JF. Fracture resistance of endodontically treated roots after restoration. J Oral Rehabil 1998;25:809-13.

25. Petersen RC. Discontinuous fiber-reinforced composites above critical length. J Dent Res 2005;84:365-70.

26. Garoushi S, Lassila LVJ, Tezvergil A, Vallittu PK. Static and fatigue compression test for particulate filler composite resin with fiber-reinforced composite substructure. Dent Mater 2007;23:17-23.

27. Xu HH, Quinn JB, Smith DT, Giuseppetti AA, Eichmiller FC. Effect of different whiskers on the reinforcement of dental resin composites. Dent Mater 2003;19:359-67.

28. Zandinejad AA, Atai M, Pahlevan A. The effect of ceramic and porous fillers on the mechanical properties of experimental dental composites. Dent Mater 2006; 22:382-7.

29. Ferracane JL, Berge HX, Condon JR. In vitro aging of dental composites in water-effect of degree of conversion, filler volume, and filler/matrix coupling. J Biomed Mat Res 1998;42:465-72.

30. Loza-Herrero MA, Rueggeberg FA, Caughman WF, Schuster GS, Lefebvre CA, Gardner FM. Effect of heating delay on conversion and strength of a post-cured resin composite. J Dent Res 1998;77:426-31.

31. Eskitascioglu G, Belli S, Kallan M. evaluation oftwo post-core systems using two different methods (fracture strength test and a finite element stress analysis study). J Endod 2002;28:629-33.

32. Vallittu PK. A review of fiber-reinforced denture base resins. J Prosthet Dent 1996;5:270-6.

33. Vallittu PK, Lassila VP, Lappalainen R. Acrylic resin-fiber composite-part I: The effect of fiber concentration on fracture resistance. J Prosthet Dent 1994;71:607-12.

34. Stipho HD. Repair of acrylic resin denture base reinforced with glass fiber. J Prosthet Dent 1998;80:546-50. 
35. Ladizesky NH, Cheng YY, Chow TW, Ward IM. Acrylic resin reinforced with chopped high performance polyethylene fiber properties and denture construction. Dent Mater 1993;9:128-35.

36. Dyer SR, Lassila LVJ, Jokinen M, Vallittu PK. Effect of fiber position and orientation on fracture load of fiber reinforced composite. Dent Mater 2004;20:947-55.

37. Vallittu PK. The effect of void space and polymerization time on transverse strength of acrylic-glass fiber composite. J Oral Rehabil 1995;22:257-61.

38. Miettinen VM, Vallittu PK. Water sorption and solubility of glass fiber-reinforced denture polymethyl methacrylate. J Prosthet Dent 1997;77:531-4.

39. Vishu S. Handbook of plastic testing technology. 2nd ed. New York: John Wiley; 1998. p. 546.

40. Yalçin E, Çehreli M, Canay Ş. Fracture resistances of cast metal and ceramic dowel and core restorations: A pilot study. J Prosthodont 2005;14,84-90.

41. Sungur DD, Ersu B, Tezvergil-Mutluy A, Canay S. The fracture resistance of composite core materials reinforced by varying fiber orientations. Int J Prosthodont 2017;30:25-6.

42. Aggarwal V, Singla M, Miglani S, Kohli S. Comparative evaluation of fracture resistance of structurally compromised canals restored with different dowel methods. J Prosthodont 2012 ;21:312-6.

43. Newman MP, Yaman P, Dennison J, Rafter M, Billy E. Fracture resistance of endodontically treated teeth restored with composite posts. J Prosthet Dent 2003;89:360-7.

44. Amin RA, Mandour MH, Abd El-Ghany OS. Fracturd strength and nanoleakage of weakened roots reconstructed using relined glass fiber-reinforced dowels combined with a novel prefabricated core system. J Prosthodont 2014;23:484-94.

45. Zicari F, Van Meerbeek B, Scotti R, Naert I. Effect of fiber post length and adhesive strategy on fracture resistance of endodontically treated teeth after fatigue loading. J Dent 2012;40:312-21.

46. Loney RW, Moulding MB, Ritsco RG. The effect of load angulation on fracture resistance of teeth restored with cast post and cores and crowns. Int J Prosthodont 1995; 8:247-251. 